\title{
Seismic performance of double-unit tunnel form building under in-plane lateral cyclic loading
}

\author{
N. H. Hamid, S. M. Saleh \& S. A. Anuar \\ Faculty of Civil Engineering, Universiti Teknologi MARA, Malaysia
}

\begin{abstract}
The seismic performance of one-third scale double units three-storey tunnel form reinforced concrete building tied up with foundation beam tested under in-plane lateral cyclic loading are performed and analysed in this paper. This building is designed according to BS 8110 , constructed in heavy structural laboratory and tested under in-plane lateral cyclic loading using displacement control method. The specimen is tested on a strong floor starting from $\pm 0.01 \%$ drift until $\pm 1.25 \%$ drift with an increment of $\pm 0.25 \%$ drift. From visual observation, the initial crack starts at $+0.25 \%$ drift with more cracks observed at $+1.0 \%$ drift. The ultimate lateral strength is reached at $+1.25 \%$ drift and the experiemental work is stopped at this drift due to the danger of collapsing the tunnel form $\mathrm{RC}$ building. Based on the experimental hysteresis loops, the ultimate in-plane lateral strength is $93 \mathrm{kN}$, maximum displacement ductility $\left(\mu_{\Delta}\right)$ is 2.5 , average elastic stiffness is $6.11 \mathrm{kN} / \mathrm{mm}$, average secant stiffness is $2.94 \mathrm{kN} / \mathrm{mm}$ and equivalent viscous damping (EVD) for the first cycle is $15 \%$ and second cycle is $6 \%$. It can be concluded that this type of building will survive in a low to moderate earthquake but will collapse in a strong or severe earthquake due to the existence of a plastic hinge zone at wall-foundation interfaces.

Keywords: ductility, equivalent viscous damping, hysteresis loops, tunnel form building, elastic stiffness, second stiffness, lateral strength.
\end{abstract}

\section{Introduction}

Tunnel form is a formwork system that allows the walls and slabs in one operation on a daily cycle with good quality product of RC buildings at site. Tunnel form buildings have load bearing wall without beam and columns are 
commonly constructed in severe and low seismic countries such as Japan, Chile, Italy, Iran, Turkey, Malaysia and others countries. Walls in tunnel form buildings have two functions: resisting lateral loads as well as carrying vertical loads [1]. The walls also can provide higher lateral stiffness and strength in order to cater for larger amount of seismic energy and minimize the damage of the structures [2]. Tunnel form building behaves well in several earthquake events such as the 1999 Kocaeli Earthquake, the 1999 Duzce Earthquake, the 2004 Bingol Earthquake and the 1964 Alaska Earthquake [3-5]. Thus, tunnel form building provides better seismic performance in addition to their low construction cost as compared to the conventional RC buildings. This in turn makes them as an alternative buildings type to more base-isolated buildings [6].

Malaysia is still considered as a low seismic region under long-distant earthquake from Sumatra and near-field earthquakes from Bukit Tinggi and Kuala Lumpur fault line [7]. However, Sabah had experienced partial damages of reinforced concrete school building when earthquake with magnitude 4.3 scale Richter. These levels of damages indicate that the overall performance of a structure which designed using BS8110 could not sustain under low magnitude of seismic loading. If any unpredicted earthquake happened within $300 \mathrm{~km}$ from the epicenter to Malaysia, a major collapse of these buildings may occur. Some studies had been conducted on wall-slab connection for tunnel form system which was designed using BS8110 using two types of wall-slab connection [8] and anchorage wall-slab connection of tunnel form building under out-of plane loading [9]. Further study was carried out by Anuar and Hamid [10] on single unit of 3-storey tunnel form building subjected to in-plane cyclic loading. Cracks were observed at the wall surface and wall slab joint of the first and second floor of tunnel form building. However, further investigation need to be carried out for double unit of tunnel form buildings under in-plane cyclic loading as these buildings were constructed using more than single unit. Therefore, the aim of this paper is to investigate the seismic performance of double unit of 3-storey tunnel form RC building when subjected to in-plane lateral cyclic loading. The focus will be in the mode of failure, lateral strength, stiffness, ductility and equivalent viscous damping. The performance of this building depends on design detailing, amount of transverse and longitudinal reinforcement, workmanship and orientation of the buildings subjected to earthquake loading.

\subsection{Design of prototype tunnel form building}

The scope of this study is limited to one-third scale double unit of 3- storey tunnel form building tested in Heavy Structural Laboratory, Universiti Teknologi MARA, Malaysia. The specimen was constructed and tested under in-plane lateral cyclic loading using double actuator with control displacement method. The specimen is constructed only for the one third (1/3) from the actual size. The limited working space and height of the laboratory are the main reasons of scaling down actual specimen size. Table 1 shows the dimensions of the onethird scale double unit tunnel form building.

There are three main stages in carrying out the research of 3-storey tunnel form building. The first stage is to design double unit tunnel form building using 
British Standard (BS8110) without considering earthquake load, followed by construction of specimen and finally, instrumentation set-up and testing. Table 2 shows the material properties such as concrete compressive strength and reinforcement bars used for the specimen. Figure 1 shows the prototype specimen of one-third scale double unit with 3-storey tunnel form building which will be constructed, tested and analyzed the seismic behavior in this paper.

Table 1: Dimensions of the prototype model.

\begin{tabular}{|c|l|l|l|}
\hline Items & \multicolumn{1}{|c|}{ Description } & \multicolumn{1}{c|}{ Actual size } & \multicolumn{1}{c|}{ Prototype specimen } \\
\hline 1. & Foundation & $\begin{array}{l}\text { Width }=5850 \mathrm{~mm} \\
\text { Length }=4000 \mathrm{~mm} \\
\text { Thickness }=500 \mathrm{~mm}\end{array}$ & $\begin{array}{l}\text { Width }=2250 \mathrm{~mm} \\
\text { Length }=1750 \mathrm{~mm} \\
\text { Thickness }=400 \mathrm{~mm}\end{array}$ \\
\hline 2. & Shear wall & $\begin{array}{l}\text { Height }=2800 \mathrm{~mm} \\
\text { Length }=3600 \mathrm{~mm} \\
\text { Thickness }=150 \mathrm{~mm}\end{array}$ & $\begin{array}{l}\text { Height }=930 \mathrm{~mm} \\
\text { Length }=1200 \mathrm{~mm} \\
\text { Thickness }=50 \mathrm{~mm}\end{array}$ \\
\hline 3. & Slab & $\begin{array}{l}\text { Width }=2700 \mathrm{~mm} \\
\text { Length }=3600 \mathrm{~mm} \\
\text { Thickness }=150 \mathrm{~mm}\end{array}$ & $\begin{array}{l}\text { Width }=900 \mathrm{~mm} \\
\text { Length }=1200 \mathrm{~mm} \\
\text { Thickness }=50 \mathrm{~mm}\end{array}$ \\
\hline
\end{tabular}

Table 2: Material properties of concrete, reinforcement bars and aggregate.

\begin{tabular}{|c|c|c|}
\hline Items & \multicolumn{1}{|c|}{ Material description } & Properties \\
\hline 1. & $\begin{array}{r}\text { Compressive concrete strength } \\
\text { (a) Foundation }\end{array}$ & $\begin{array}{r}\text { (a) } 40 \mathrm{~N} / \mathrm{mm}^{2} \\
\text { (b) } 35 \mathrm{~N} / \mathrm{mm}^{2}\end{array}$ \\
\hline 2. & $\begin{array}{r}\text { Yield strength of reinforcement bar } \\
\text { (a) Foundation and Deep Beam }\end{array}$ & $\begin{array}{l}\text { (a) } 460 \mathrm{~N} / \mathrm{mm}^{2} \\
\text { (b) } 250 \mathrm{~N} / \mathrm{mm}^{2}\end{array}$ \\
\hline 3. & $\begin{array}{l}\text { Aggregate size } \\
\text { (a) Foundation and Deep Beam }\end{array}$ & (a) $20 \mathrm{~mm}$ \\
& (b) Shear Wall and Slab $10 \mathrm{~mm}$ \\
\hline
\end{tabular}

Figure 2 shows the detailed drawing of the wall panel for each level of 3storey tunnel form building. The overall dimension of wall panel is $1200 \mathrm{x}$ 930x $50 \mathrm{~mm}$. Wall panel is designed to carry only vertical loading from the roof and concrete slab which include dead load and imposed load. A single layer of reinforcement bar with diameter of $8 \mathrm{~mm}\left(\mathrm{f}_{\mathrm{y}}=250 \mathrm{~N} / \mathrm{mm}^{2}\right)$ were used for the wall panel. The longitudinal spacing between the bars is $80 \mathrm{~mm}$ and the transverse spacing between reinforcement bars for the wall is $200 \mathrm{~mm}$.

Figure 3 shows the loading regime for testing procedure of tunnel form building using displacement control method. The initial drift imposed on the building is $\pm 0.01 \%$ drift for two cycles for each drift. After that followed by $\pm 0.1 \%$ drift, $\pm 0.25 \%$ drift, $\pm 0.5 \%$ drift, $\pm 0.75 \%$ drift and $\pm 1.0 \%$ drift. For each drift, the experimental should be conduct until the specimen until crack and failed under buckling or fracture of reinforcement bars. 


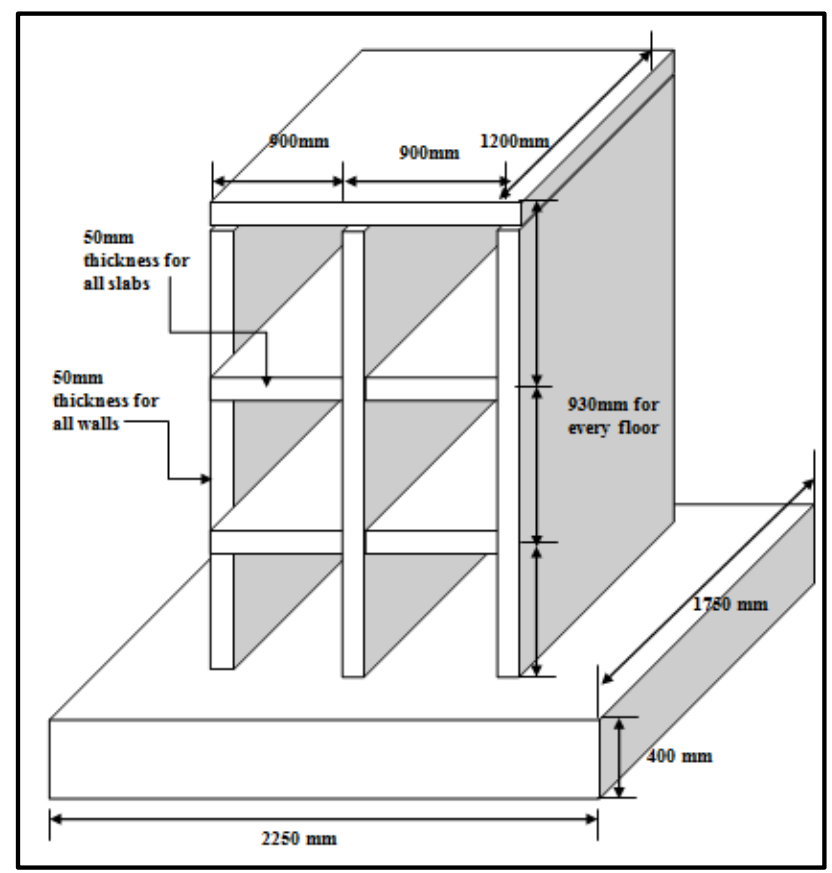

Figure 1: One-third scale double unit of prototype tunnel form building.

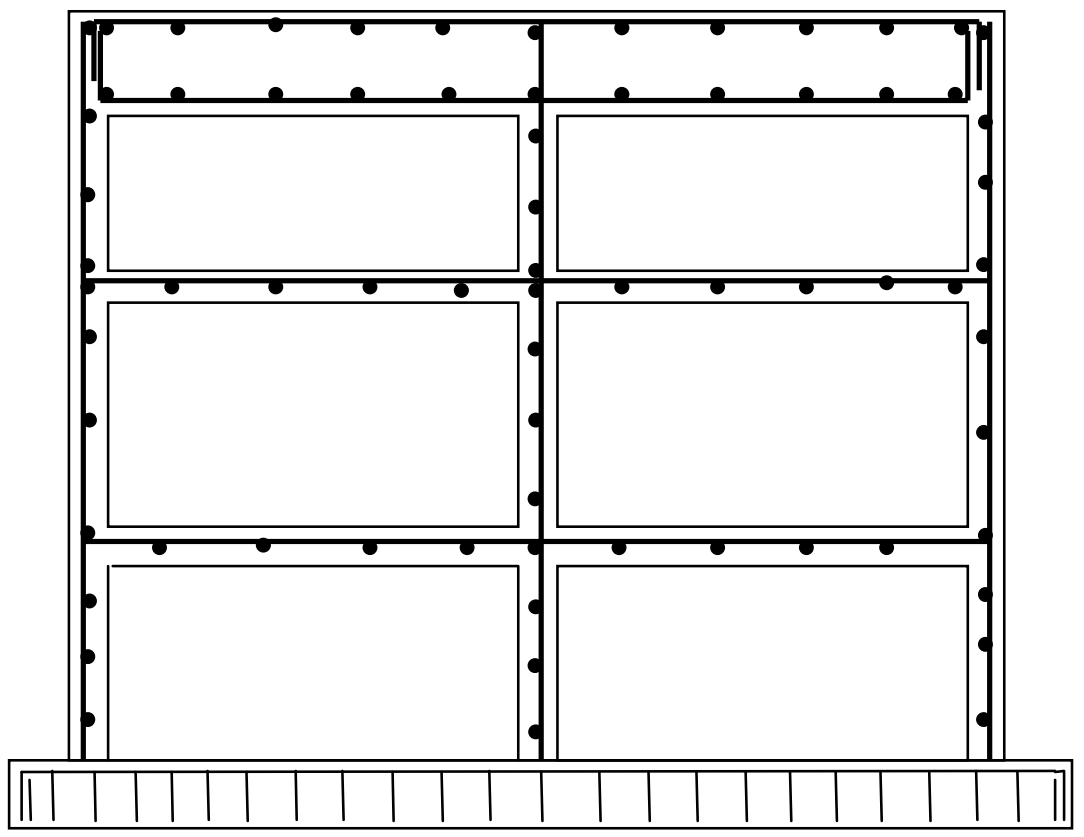

Figure 2: Detailed drawing for three-storey tunnel form building. 


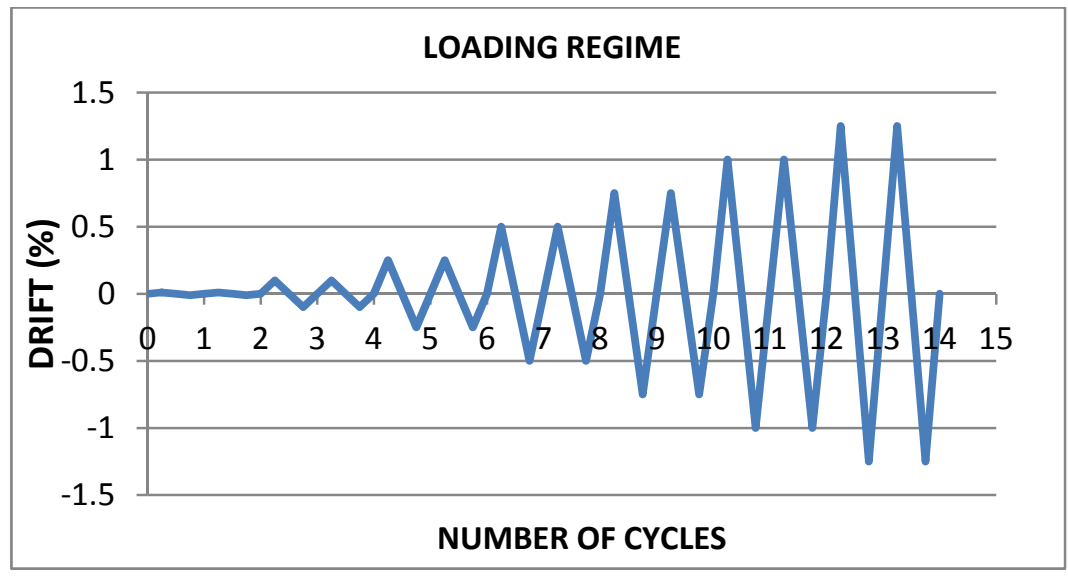

Figure 3: Loading regime for testing.

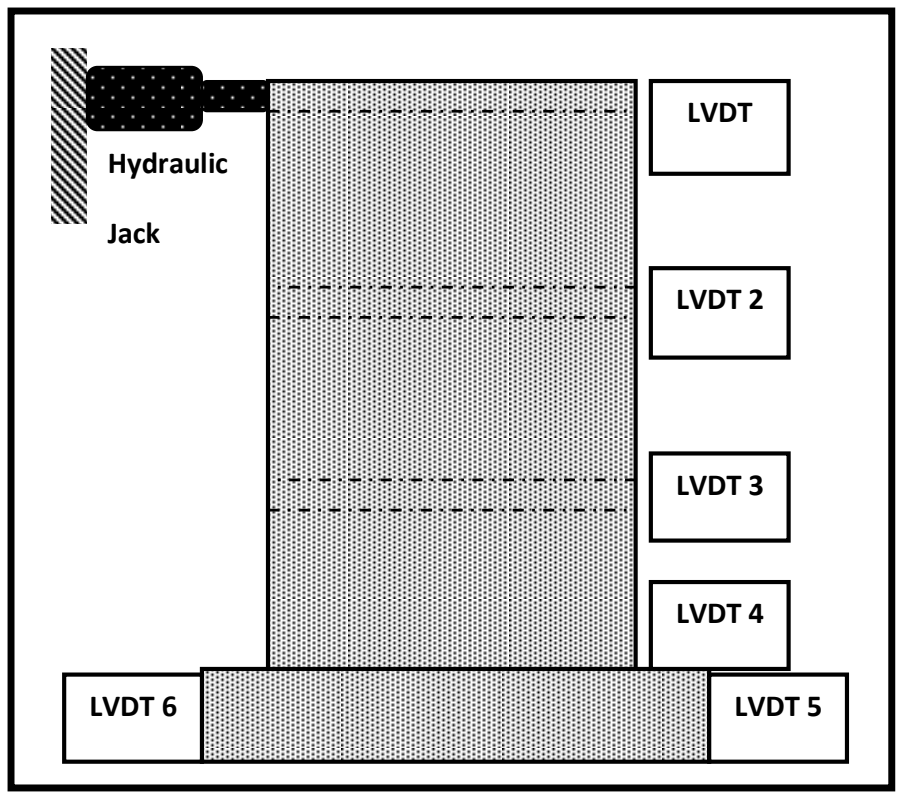

Figure 4: Experimental set-up and location of LVDTs installed on the specimen.

Figure 4 shows the locations of linear potentiometers (LVDT) on top of the surface and side of the wall panel. Four (4) numbers of LVDTs were used to measure the lateral displacement/deformation of the tunnel RC building and two (2) numbers of LVDTs for foundation beam when subjected to in-plane lateral cyclic loading. The effective in-plane lateral displacement of the specimen was monitored by one linear potentiometers aligned with actuator providing lateral force label as LVDT. 


\section{Experimental result}

\subsection{Visual observation}

During testing, the cracking was observed at wall-foundation interface when the lateral drift of $\pm 0.25 \%$ applied at top of the building. The first crack was occurred on Wall 1 which is still considered under elastic condition. Figure 5 shows the cracks occurred at the inner and outer surface Wall 1. The load was recorded as $25 \mathrm{kN}$ when the first crack occurred at bottom of the wall. The horizontal crack was observed along the surface of the wall which in-line with horizontal tension force applied to the building. Second crack was occurred on Wall 2. Figure 6 shows the distribution of cracks on the inner and outer surface

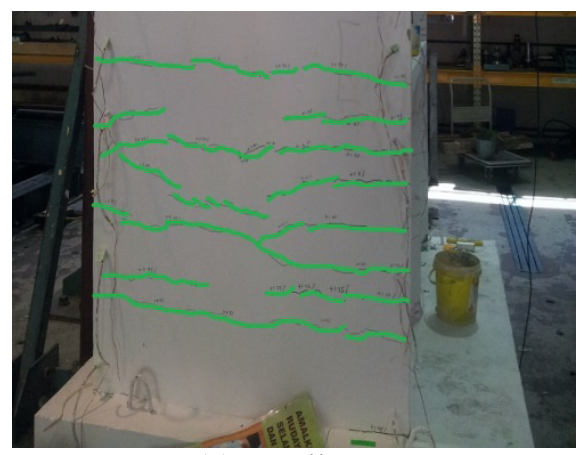

(a) Wall 1-Outer

Figure 5: Cracks were observed on Wall 1; (a) Wall 1-Outer, and (b) Wall 1-Inner.

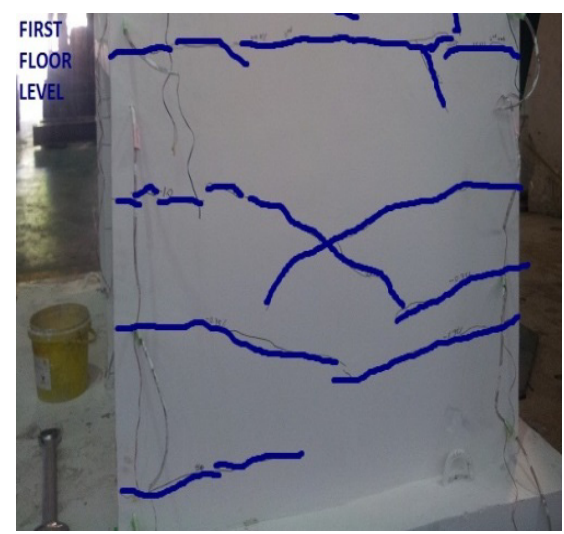

(a) Wall 2-Outer

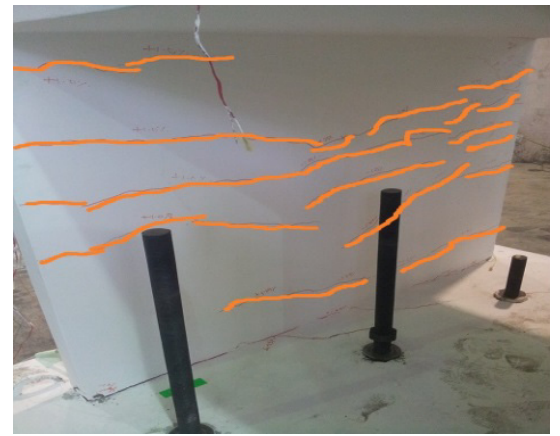

(b) Wall 1-Inner

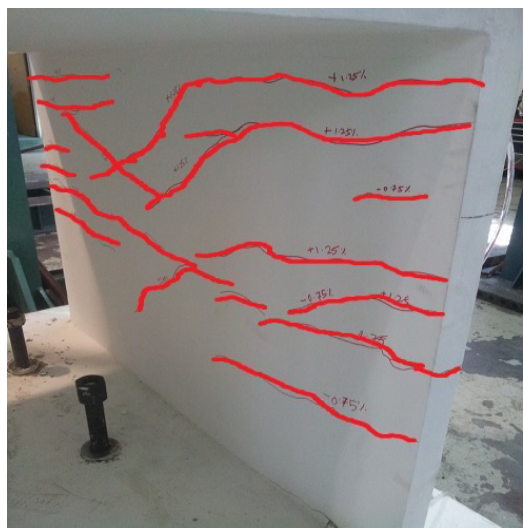

(b) Wall 2-Inner

Figure 6: Cracks were observed on Wall 3; (a) Wall 3-Outer; and (b) Wall 3Inner. 
of Wall 2. The similar crack has happened at every surface of the wall. The major crack was occurred at first floor level followed by second floor and minor crack occurred at the concrete slab. However, there was no crack occurred at third floor. Spalling of concrete was observed at wall-foundation interfaces when $+1.0 \%$ drift was applied at top of the building.

Figure 7 shows the spalling of concrete and cracks at the right hand side of Wall 2 and major cracks on the left when $+1.0 \%$ drift was applied. Most of the cracks were occurred at ground level where the lateral load and vertical load were transfer to the foundation beam. Furthermore, the existence of a plastic hinge zone at the bottom of the wall cause the spalling of concrete and buckling of longitudinal reinforcement bars. During testing, both corners of the wall experienced opening and closing the gap where during pushing one corner experienced tension zone and the other corner was experienced compression zone or vice versa in pulling direction. As the amplitude of lateral displacement increases, the opening gap becomes wider (tension zone) and closing gap (compression zone) becomes narrower. This phenomenon will cause an increasing in length of plastic hinge and more cracks were observed along left and right hand side of the wall panel. Initially, the tunnel form building was experienced the elastic behavior between $\pm 0.01 \%$ drift until $\pm 0.5 \%$ drift where only surface cracks were observed on the wall. After yielding limit, the building behaved inelastic (plastic zone) starting from $\pm 0.75 \%$ drift until $\pm 1.25 \%$ drift where spalling of concrete were observed and fracture of longitudinal bar.

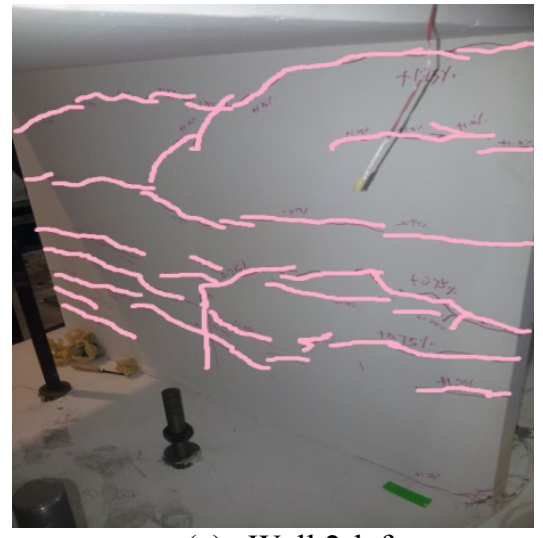

(a) Wall 2-left

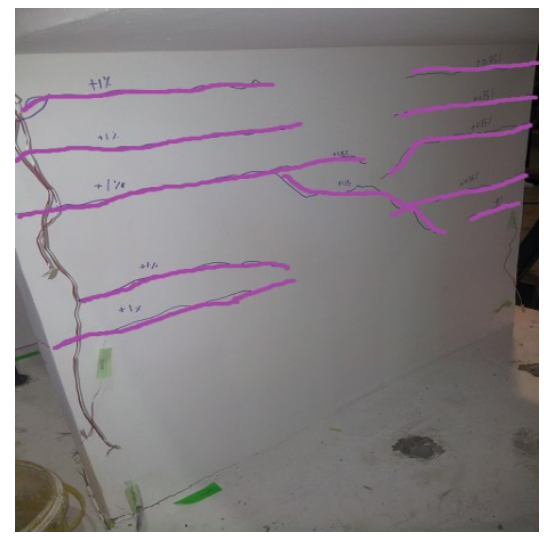

(b) Wall 2-right

Figure 7: Spalling of concrete and cracks were observed on Wall 2; (a) Wall 2left; and (b) Wall 2-right.

\subsection{Hysteresis loops}

A hysteresis loop is the lateral movement of a sample under one cycle of cyclic loading starting from zero load and displacement and finished at the original position. A graph of lateral load versus displacement can be represented as hysteresis loop as shown in Figure 8. Maximum lateral displacement, stiffness, 
ductility and equivalence viscous damping can be obtained from hysteresis loop. From Figure 8, the maximum lateral load was $64.67 \mathrm{KN}$ at $+1.0 \%$ drift in pushing direction and the measured lateral displacement was $26.7 \mathrm{~mm}$. At this stage, the building was experienced the inelastic behavior where a lot of cracks were observed on the surface of the wall and buckling of longitudinal reinforcement bars.

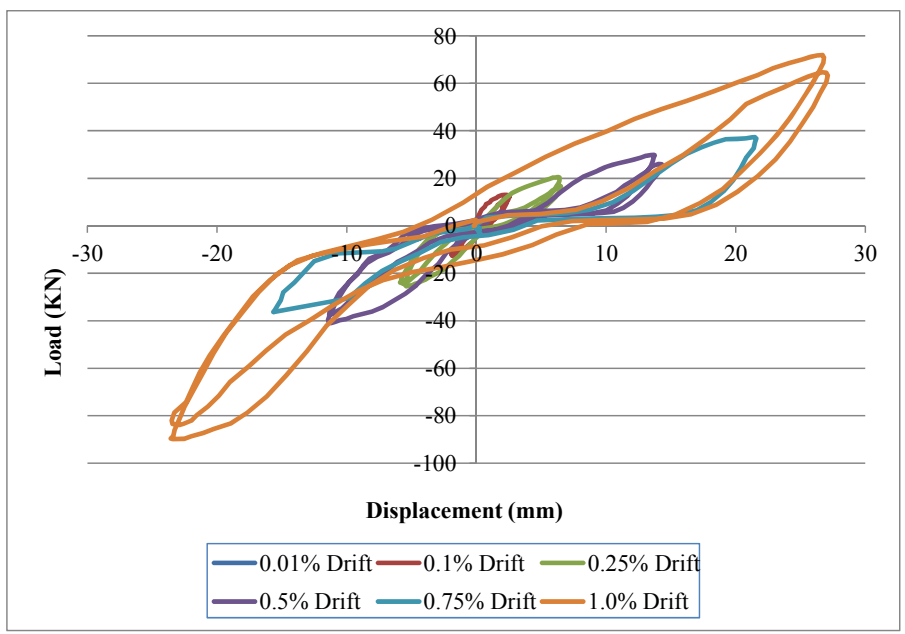

Figure 8: Hysteresis loops for LVDT of tunnel form building.

\subsection{Stiffness and ductility}

Stiffness can be defined as the extent to which a structure can resist loading with no significant displacement or it is the ratio of lateral load versus displacement. There are two categories of stiffness known as elastic stiffness and secant stiffness. For in-plane response of the 3-storey tunnel form building, it is experiencing the elastic stiffness during elastic zone and secant stiffness under plastic zone. For every cycle of drift, the building experiences difference stiffness depending on the amount of lateral load imposed on the structures and its' directions. Table 3 shows the values of elastic and secant stiffness in pushing direction. The average elastic stiffness is $7.42 \mathrm{kN} / \mathrm{mm}$ and average secant stiffness is $2.67 \mathrm{kN} / \mathrm{mm}$ in pushing direction. Table 4 shows the average elastic stiffness is $13.89 \mathrm{kN} / \mathrm{mm}$ and average secant stiffness is $4.14 \mathrm{kN} / \mathrm{mm}$ in pulling direction. Thus, it can be concluded that the secant stiffness has one-third value of elastic stiffness and the pulling direction has bigger elastic and secant stiffness compared to the pushing direction.

Ductility is the physical property of a material where it is capable of sustaining large permanent changes in shape without breaking. In seismic design, ductility plays an important role in stability and integrity of the structures. From Table 3, the ultimate displacement ductility of tunnel form building is 1.95 in pushing direction and 2.06 in pulling direction. The average ductility $\left(\mu_{\Delta}\right)$ of 2 is 
insufficient to resist the moderate to severe earthquake loadings. Therefore, this tunnel form building will not survive or unsafe under these conditions of earthquake loads.

Table 3: Elastic, secant stiffness and ductility for pushing direction.

\begin{tabular}{|c|c|c|c|c|c|}
\hline \multirow{2}{*}{ Drift (\%) } & \multicolumn{5}{|c|}{ PUSHING } \\
\cline { 2 - 6 } & Load (kN) & Disp. (mm) & $\begin{array}{c}\text { Elastic stiffness } \\
(\mathrm{kN} / \mathrm{mm})\end{array}$ & $\begin{array}{c}\text { Secant stiffness } \\
(\mathrm{kN} / \mathrm{mm})\end{array}$ & Ductility \\
\hline 0.01 & 2.77 & 0.5 & 5.54 & - & 0.09 \\
\hline 0.1 & 13.08 & 2.3 & 5.69 & - & 0.168 \\
\hline 0.25 & 20.49 & 5.64 & 11.03 & - & 0.412 \\
\hline 0.5 & 29.89 & 13.68 & - & 2.18 & 1.000 \\
\hline 0.75 & 37.37 & 19.84 & - & 3.14 & 1.450 \\
\hline 1.0 & 64.67 & 26.7 & - & 2.69 & 1.951 \\
\hline
\end{tabular}

Table 4: Elastic, secant stiffness and ductility for pulling direction.

\begin{tabular}{|c|c|c|c|c|c|}
\hline \multirow{2}{*}{$\begin{array}{c}\text { Drift } \\
(\%)\end{array}$} & \multicolumn{5}{|c|}{ PULLING } \\
\cline { 2 - 6 } & Load (kN) & Disp. (mm) & $\begin{array}{c}\text { Elastic stiffness } \\
(\mathrm{kN} / \mathrm{mm})\end{array}$ & $\begin{array}{c}\text { Secant stiffness } \\
(\mathrm{kN} / \mathrm{mm})\end{array}$ & Ductility \\
\hline 0.01 & 1.87 & 0.1 & 18.7 & - & 0.008 \\
\hline 0.1 & 12.78 & 1.8 & 7.1 & - & 0.159 \\
\hline 0.25 & 76 & 4.78 & 15.89 & - & 0.422 \\
\hline 0.5 & 40.92 & 11.32 & - & 3.62 & 1.00 \\
\hline 0.75 & 76 & 15.36 & - & 4.95 & 1.357 \\
\hline 1.0 & 89.8 & 23.4 & - & 3.84 & 2.06 \\
\hline 1.25 & - & - & - & - & - \\
\hline
\end{tabular}

\subsection{Equivalent viscous damping (EVD)}

Equivalent viscous damping (EVD) is a measurement of energy dissipated amount during the load applied to the structure. In this paper, the percentage EVD is calculated in two separate loops that recognize first and second cycles. The EVD percentage is obtained from $0.1 \%$ drift until $1.25 \%$ drift for both pushing and pulling phase. The calculation of equivalent viscous damping is formulated in equation (1) as follows:

$$
\xi_{e q}=\left[\left(\frac{1}{4 \pi}\right) \times\left(\frac{E_{D}}{E_{s o}}\right)\right] \times 100
$$

$\xi_{e q}$ is equivalent viscous damping, $\mathrm{E}_{\mathrm{D}}$ is energy dissipated within one loop of load versus displacement measured using the area of trapezium and $\mathrm{E}_{\mathrm{so}}$ is strain energy calculated the area of triangle.

Figure 9 shows the percentage of equivalent viscous damping (EVD) of 3storey tunnel form building. Maximum energy absorption comes from the first cycle with $15.6 \%$ of EVD obtained from $0.25 \%$ drift and it dropped linearly until $0.5 \%$ drift. This phenomenon indicates that the amount of energy released from 
the structure and caused the appearance of cracks and concrete sealing. But at the same drift $(0.5 \%)$ the EVD started to increase until $0.75 \%$ drift and stopped at $13.45 \%$. EVD percentages for the second cycle started at $6.60 \%$ at $0.1 \%$ drift and increased to $7.28 \%$ at $0.25 \%$ drift. However, at $0.5 \%$ drift the EVD dropped to $12.78 \%$ but increased until $1.0 \%$ drift with $11.57 \%$. This indicated that the structure dissipated much more energy during the pushing phase rather than pulling phase.

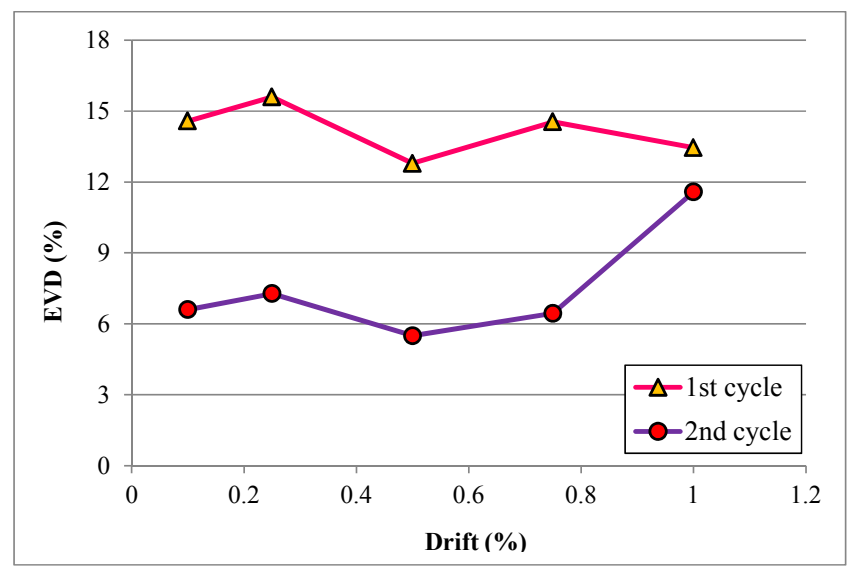

Figure 9: Equivalent viscous damping versus drift for two cycles.

\section{Conclusions and recommendations}

The conclusions and recommendations for this paper are as follows:

a) The ultimate lateral load is $102.82 \mathrm{kN}$ when $+1.25 \%$ drift applied to the tunnel form building.

b) The building experiences elastic behavior when the drift started from $0.01 \%$ drift and behaves inelastic behavior starting from $0.5 \%$ drift until $1.25 \%$ drift. However, one cycle of drift was applied at $+1.25 \%$ drift due to the instability of the building.

c) The elastic stiffness has three times bigger than secant stiffness and the pulling direction has bigger elastic and secant stiffness than in pushing directions.

d) The overall displacement ductility of double unit three-storey tunnel building is 2 and this building is not safe to survive under moderate and severe earthquake.

e) The equivalent viscous damping for first cycle is bigger that second cycle. This is because the first earthquake strikes will need more energy to 
overcome the lateral capacity strength of the structure than second strikes where the structure become unstiffened and the construction materials behave inelastically.

f) It is recommended that the tunnel form building is designed, tested and analysis in series direction rather than in parallel direction. This is due to the fact that the series arrangement of this building has bigger lateral strength capacity as compare to the parallel arrangement.

\section{Acknowledgements}

The author would like to thank the Research Management Institute (RMI), University Teknologi MARA and Fundamental Research Grant Scheme (FRGS) for the funding this research work. Nevertheless, the authors also would like to express their gratitude to the technicians of Heavy Structures Laboratory, the Faculty of Civil Engineering, UiTM for conducting this research work successfully.

\section{References}

[1] Tavafoghi, A. and Eshgi, A., Seismic Behavior of Tunnel Form Concrete Building Structures, The $14^{\text {th }}$ of World Conference on Earthquake Engineering, Beijing, China, October 12-17, 2008.

[2] Kwan, A. K. H and Xian, J. Q. Shake-Table Tests of Large Scale Shear Wall and Infilled Frame Models, Proc. Instn, Civ, Engrs. Structs \& Bldgs, 66-77, Feb 1995.

[3] Kalkan, E., and Bahadir, Y. S., Pros and Cons of Multistory RC TunnelForm (Box-Type) Buildings, The Structural Design of Tall and Special Buildings, 2007.

[4] Fintel, M., Performance of buildings with shear walls in earthquakes in the last thirty years. PCI Journal, 40 (3), 62-80, 1995.

[5] Berg, G. V., and Stratta, J. L. (1964). Anchorage and the Alaska Earthquake on March 27, 1964. American Iron and Steel Institute, 63, 1964.

[6] Balkaya, C. and Kalkan, E., Seismic Vulnerability, Behaviour and Design of Tunnel Form Building Structures, Engineering Structures, 2081-2099, 26, 2004.

[7] Adnan, K. The Effect of the Latest Sumatra Earthquake to Malaysian Peninsular. Journal of civil engineering, Vol. 15 No. 2, 2002.

[8] Al-Aghbari, A., Hamzah, S. H., Hamid, N. H. and Rahman, N. Structural Performance of two types of Wall Slab Connection Under Out-of-Plane Lateral Cyclic Loading, Journal of Engineering Science and Technology, Vol. 7, No. 2, 177-194, 2012.

[9] Hamid, N. H., and Masrom, M. A., Seismic Performance of Wall-Slab Joints in Industrialized Building System (IBS) Under Out-Of-Plane 
Reversible Cyclic Loading, IACSIT International Journal of Engineering and Technology, Vol. 4, No. 1., 26-33, 2012.

[10] Anuar, S. A. and Hamid, N. H, Seismic Performance of Single Unit Tunnel Form Building subjected to in-plane cyclic loading, International Postgraduate Seminar, Faculty of Civil Engineering, Universiti Teknologi MARA, Shah Alam, Selangor, Malaysia, 25-26 June 2013. 